\title{
Event-related potential responses to love-related facial stimuli
}

Citation for published version (APA):

Langeslag, S. J. E., Schmitt, B. M., Franken, I. H. A., \& Van Strien, J. W. (2007). Event-related potential responses to love-related facial stimuli. Biological Psychology, 76(1-2), 109-115.

https://doi.org/10.1016/j.biopsycho.2007.06.007

Document status and date:

Published: 01/01/2007

DOI:

10.1016/j.biopsycho.2007.06.007

Document Version:

Publisher's PDF, also known as Version of record

Document license:

Taverne

Please check the document version of this publication:

- A submitted manuscript is the version of the article upon submission and before peer-review. There can be important differences between the submitted version and the official published version of record.

People interested in the research are advised to contact the author for the final version of the publication, or visit the DOI to the publisher's website.

- The final author version and the galley proof are versions of the publication after peer review.

- The final published version features the final layout of the paper including the volume, issue and page numbers.

Link to publication

\footnotetext{
General rights rights.

- You may freely distribute the URL identifying the publication in the public portal. please follow below link for the End User Agreement:

www.umlib.nl/taverne-license

Take down policy

If you believe that this document breaches copyright please contact us at:

repository@maastrichtuniversity.nl

providing details and we will investigate your claim.
}

Copyright and moral rights for the publications made accessible in the public portal are retained by the authors and/or other copyright owners and it is a condition of accessing publications that users recognise and abide by the legal requirements associated with these

- Users may download and print one copy of any publication from the public portal for the purpose of private study or research.

- You may not further distribute the material or use it for any profit-making activity or commercial gain

If the publication is distributed under the terms of Article $25 \mathrm{fa}$ of the Dutch Copyright Act, indicated by the "Taverne" license above, 


\title{
Event-related potential responses to love-related facial stimuli
}

\author{
Sandra J.E. Langeslag ${ }^{\mathrm{a}, *}$, Bernadette M. Jansma ${ }^{\mathrm{b}}$, \\ Ingmar H.A. Franken ${ }^{\mathrm{a}}$, Jan W. Van Strien ${ }^{\mathrm{a}}$ \\ ${ }^{a}$ Erasmus University Rotterdam, Institute of Psychology, Erasmus Affective Neuroscience Lab, P.O. Box 1738, NL-3000 DR Rotterdam, The Netherlands \\ ${ }^{\mathrm{b}}$ Maastricht University, Faculty of Psychology, Department of Cognitive Neuroscience, P.O. Box 616, NL-6200 MD Maastricht, The Netherlands
}

Received 21 December 2006; accepted 29 June 2007

Available online 3 July 2007

\begin{abstract}
In event-related potential (ERPs) studies, emotional stimuli usually elicit an enhanced late positive potential (LPP), which is assumed to reflect motivated attention. However, whether a stimulus elicits emotional responses may depend on the individual's state, such as experiencing romantic love. It has been suggested that stimuli that are related to someone's beloved will elicit increased attention in that infatuated individual. In this study, participants who were in love viewed faces of their beloved, their friend, and of an unknown, beautiful person. The friend was included to control for familiarity, and the unknown person for perceived beauty. As expected, the LPP was larger in response to the face of the beloved than to the other two emotionally significant faces. Interpreting the LPP as reflecting motivated attention, this implies that romantic love is accompanied by increased attention for the face of one's beloved.
\end{abstract}

(C) 2007 Elsevier B.V. All rights reserved.

Keywords: Love; Attention; Event-related potentials (ERPs); Late positive potential (LPP)

\section{Introduction}

Almost everybody has been deeply in love sometime and therefore knows that love is accompanied by physical symptoms, such as trembling, palpitations, and reduced hunger. Recently, scientists have started to investigate the biological and neural basis of romantic love, for example using functional magnetic resonance imaging (Bartels and Zeki, 2000; Aron et al., 2005). Event-related potentials (ERPs), however, have not yet been employed to investigate romantic love, although they have extensively been used to study other emotions and motivations. ${ }^{1}$ In previous studies, emotional stimuli have consistently been found to elicit enlarged late (emerging around 300-400 ms after stimulus onset), positive components of the ERP waveform compared to neutral stimuli. These late positive components have a centro-parietal distribution and a parietal maximum. The positivity from about $400 \mathrm{~ms}$ after stimulus onset has inconsistently been labeled late positive potential

\footnotetext{
* Corresponding author. Tel.: +31 10408 2663; fax: +31 104089009 .

E-mail address: langeslag@ @sw.eur.nl (S.J.E. Langeslag).

${ }^{1}$ Romantic love is probably a motivational state rather than an emotion, but the discussion regarding this issue is beyond the scope of this article and can be found elsewhere (e.g. Aron et al., 2006, 2005; Langeslag, 2006).
}

(LPP) (e.g. Schupp et al., 2004a), late positive component (LPC) (e.g. Ashley et al., 2004), and positive slow wave (PSW) (e.g. Amrhein et al., 2004). Here the term LPP will be used to describe this late positivity. The LPP has been found to be greater for emotional words (Dietrich et al., 2000), emotional pictures (Amrhein et al., 2004; Cuthbert et al., 2000; Dolcos and Cabeza, 2002; Pollatos et al., 2005), and faces with emotional expressions (Eimer and Holmes, 2002; Johansson et al., 2004; Schupp et al., 2004b) than for neutral stimuli. Because the LPP is enhanced for both unpleasant and pleasant stimuli, it is generally assumed to be sensitive to arousal rather than to valence (Schupp et al., 2006).

The LPP is also enhanced for emotionally neutral, but taskrelevant stimuli. Target stimuli that occur infrequently among distractor stimuli, for example, elicit larger LPPs than the distractor stimuli do (Picton, 1992). Therefore, it is assumed that the LPP reflects attentional processes. This, combined with the fact that emotional stimuli tend to demand allocation of attention (Compton, 2003) because they signal important information regarding reproduction and survival (LeDoux, 1996), has led to the suggestion that the enlarged LPP in response to emotional stimuli also reflects an attentional process. This attentional process has been called motivated attention, since it is evoked by stimuli that trigger motivational 
processes such as approach or avoidance (Schupp et al., 2004a). The results of a study by Schupp et al. (2007) are in line with the idea that the increased LPP to emotional stimuli reflects attention. In that study, participants had to count either the pleasant, neutral or the unpleasant pictures, which all occurred with equal probability. The LPP appeared larger for both target and emotional pictures, and moreover, these effects augmented each other. This implies that the LPP reflects task-induced as well as motivated attention.

While a picture of a wounded person or the word "rape" will elicit emotional arousal and motivated attention in the large majority of people, other stimuli will elicit emotional responses in certain individuals only. Spider-related words, for example, capture attention more than neutral words especially in spiderphobics (e.g. Lipp and Waters, 2007). Similarly, Fisher (1998, 2000) has suggested that someone who is in love will allocate more attention to his or her beloved than to another person, whereas both persons would be equally interesting to an outsider. Fisher et al. (2002) further proposed that this increased attention for the beloved would contribute to the fact that infatuated people feel that their beloved is unique, that they focus their attention on the positive qualities of the beloved and that people are in love with one person at a time only. It is reasonable to assume that stimuli related to the object of one's romantic feelings, like other motivational and emotional stimuli, would elicit motivated attention because they play an important role in the evolutionary process of reproduction (Fisher, 1998, 2000, 2004).

Indeed, the personal significance of a certain stimulus has been found to influence the LPP amplitude in response to that stimulus. Heroin and alcohol dependent participants, for example, showed an increased LPP in response to heroin and alcohol-related pictures, respectively, while non-dependent participants did not (Franken et al., 2003; Namkoong et al., 2004). Moreover, in a study by Johnston and Oliver-Rodríguez (1997) with facial stimuli, the LPP amplitude was correlated with the perceived beauty of the faces. Interestingly, the dopaminergic reward system has been found to be activated when participants viewed beautiful faces (Senior, 2003), as well as when infatuated participants viewed the face of their beloved (Aron et al., 2005; Fisher et al., 2002, 2005). Similarly, dopamine has been implicated in drug craving elicited by drugrelated cues (Franken et al., 2005). Thus, the neurotransmitter dopamine could play a role in the signaling of personal salience of these positively valenced and rewarding stimuli.

The present study investigated event-related potentials in response to love-related facial stimuli. Considering the abovementioned findings, it can be expected that the LPP will be augmented in response to a photograph of the face of the participant's beloved compared to a photograph of an unfamiliar face. However, this comparison between the face of a beloved and the face of another arbitrary person will be confounded by variables such as familiarity and perceived beauty. In order to control for these variables, we compared the ERP response to the face of the participant's beloved with ERP responses to photographs of the participant's friend and of an unknown, beautiful person. It was expected that the photograph of the beloved would elicit a greater LPP than the photographs of the friend and unknown person. This because, in accordance with Fisher $(1998,2000)$, we expected that the face of the beloved would capture more attention than the faces of the friend and unknown person, which are not associated with romantic love but merely with familiarity or beauty.

\section{Method}

\subsection{Participants}

Participants were recruited by means of a poster at the university campus. Eighteen students (9 men, 9 women; mean age 21.5, range 18-34) volunteered to participate and gave informed consent prior to testing. Only participants who were in love with someone of the opposite sex were included. Other inclusion criteria were normal or corrected-to-normal vision, no medical diagnosis and no medication use. Furthermore, all participants were right-handed as determined by a hand preference questionnaire (Van Strien, 1992). Participants were rewarded with course credit or 10 Euros.

\subsection{Design}

The participants viewed gray-scaled photographs of the faces of their beloved, their friend, and of a beautiful person that was unknown to them. The men viewed only female faces, whereas the women viewed male faces (i.e. the beloved was of the opposite sex, the friend was of the same sex as the beloved, and the male participants viewed an unknown female, whereas female participants viewed an unknown male). The photographs the beloved and the friend were supplied by the participants and digitally scanned. The photographs of the beautiful persons had been created by blending faces that had previously been rated as very beautiful. ${ }^{2}$ Note that the participants did not detect anything unusual in these faces; they are very realistic.

To make sure that there were no objective differences in beauty between the beloved and the friends, a separate sample of men and women who did not know these faces rated their beauty on a 9-point Likert scale. Ten women (mean age 22.4, range 19-25) rated the photographs of the males, and 10 men (mean age 22.2 , range 19-30) rated the photographs of the females.

\subsection{Procedure}

At the testing session, the participants provided information about the duration of their love to the beloved, and the duration of their romantic relationship (if any) with the beloved. Furthermore, they rated the extent to which they experienced romantic love with their beloved, their friend, and the unknown person, as well as the beauty of those people, on 9-point Likert scales. The participants also completed the passionate love scale (PLS; Hatfield and Sprecher, 1978, in Hatfield, 1998), which assesses the extent to which someone experiences passionate or romantic love (minimum mean score $=1$, maximum =9). In addition, they completed the Affect Intensity Measure (AIM; Larsen, 1984 in Larsen and Diener, 1987), which determines the general tendency to experience emotions intensely (minimum mean score $=1$, $\max$ imum =6). Next, the electrodes were placed and the participants were instructed to limit movements and eye blinks during testing. The participants were seated in a comfortable chair in a soundproof, dimly lit room. They completed two independent tasks; first the one of the ERP study reported here and then a second task involving viewing the faces of the beloved and friends for $30 \mathrm{~s}$ alternatively, interleaved with a distraction task (to be reported elsewhere). Trial structure was as follows: To start, a white fixation cross was presented on a black computer screen for 600-1000 ms (pseudo randomized duration), followed by a $250 \mathrm{~ms}$ presentation of a face. Then a fixation cross was presented again for $1000 \mathrm{~ms}$, followed by a blank screen for $1000 \mathrm{~ms}$. The faces were

\footnotetext{
${ }^{2}$ From http://www.uni-regensburg.de/Fakultaeten/phil_Fak_II/Psychologie/ Psy_II/beautycheck/english/prototypen/prototypen.htm.
} 
presented in a pseudo random order, with the constraint that a specific face appeared no more than three times consecutively. Each face (beloved, friend, and unknown person) was presented 30 times, thus the study consisted of 90 trials.

Participants were instructed to focus at the fixation crosses and to attend to the faces, because they would have to answer questions about them. The questions were closed questions about the identity of the person on the previous photograph ('was the person on the previous photograph your beloved?', 'was the person on the previous photograph your friend?' or 'was the person on the previous photograph a stranger?'). Each of these questions appeared four times, pseudo randomly intermixed with the photographs. They were used to control for the participants' alertness. Participants answered the questions by pressing the left ('yes') or right ('no') button of a mouse. Note that these responses did not coincide with the presentation of the faces.

\subsection{Electroencephalogram (EEG) recording and signal processing}

The electroencephalogram (EEG) was recorded using a 32-channel amplifier and data acquisition software (ActiveTwo System, BioSemi). The $32 \mathrm{Ag}-$ $\mathrm{AgCl}$ active electrodes were placed upon the scalp by means of a head cap (BioSemi), according to the 10-20 International System (Fp1/2, AF3/4, Fz, F3/ 4, F7/8, FC1/2, FC5/6, Cz, C3/4, T7/8, CP1/2, CP5/6, Pz, P3/4, P7/8, PO3/4, Oz, $\mathrm{O} 1 / 2)$. Vertical electro-oculogram (VEOG) and horizontal electro-oculogram (HEOG) were recorded by attaching additional electrodes (UltraFlat Active electrodes, BioSemi) above and below the left eye, and at the outer canthi of both eyes. Another two electrodes were attached to the left and right mastoids (M1/2). An active electrode (CMS - common mode sense) and a passive electrode (DRL—driven right leg) were used to comprise a feedback loop for amplifier reference. All signals were digitized with a sample rate of $512 \mathrm{~Hz}$, a 24-bit A/D conversion, and a low pass filter of $134 \mathrm{~Hz}$.

Offline, a mathematically linked mastoids reference was applied and data were filtered using a $0.15-30 \mathrm{~Hz}$ band pass filter (phase shift-free Butterworth filters; $24 \mathrm{~dB}$ /octave slope). Data were segmented in epochs from $100 \mathrm{~ms}$ prestimulus until $1000 \mathrm{~ms}$ post-stimulus onset. Ocular artifact correction was applied according to the Gratton and Coles algorithm (Gratton et al., 1983). The mean $100 \mathrm{~ms}$ pre-stimulus period was used for baseline correction. Artifact rejection criteria were minimum and maximum baseline-to-peak -75 to $+75 \mu \mathrm{V}$, and a maximum allowed voltage skip (gradient) of $50 \mu \mathrm{V}$. The mean number of accepted epochs per participant per condition was 24.1 (S.D. $=4.4$ ) and the numbers of accepted epochs were similar across conditions, $F(2$, $34)<1 \mathrm{~ns}$.

\subsection{Analyses}

The ratings regarding romantic love for and beauty of the beloved, friend, and unknown beautiful person were tested using repeated measures ANOVAs with the within-subject factor condition (three levels: beloved, friend, and unknown, beautiful person). The mean ERP activity in the time windows 140 $200 \mathrm{~ms}, 200-400 \mathrm{~ms}$, and 400-700 ms was tested at the electrodes Fz, F3/4, Cz, $\mathrm{C} 3 / 4, \mathrm{Pz}$, and $\mathrm{P} 3 / 4$ using repeated measures ANOVAs with the within-subject factors caudality (three levels: frontal-F3, Fz, F4; central-C3, Cz, C4; parietal-P3, Pz, P4), laterality (three levels: left-F3, C3, P3; midline-Fz, $\mathrm{Cz}, \mathrm{Pz}$; right $-\mathrm{F} 4, \mathrm{C} 4, \mathrm{P} 4$ ), and condition (three levels: photograph of beloved, friend, and unknown beautiful person) (cf. Amrhein et al., 2004). The LPP was defined as the mean ERP activity in the 400-700 ms time segment after onset of the stimulus (Cuthbert et al., 2000). Only effects involving the factor condition were of interest and are reported. When applicable, degrees of freedom were corrected with the Greenhouse-Geisser correction. The $F$ values, the uncorrected d.f., the epsilon $(\varepsilon)$ values, and corrected probability levels are reported.

\section{Results}

\subsection{Questionnaire and behavioral data}

The mean duration of the participants' romantic love was 12.6 months (S.D. $=10.1$, range $2.5-36$ months). All partici- pants, except one female, were involved in a romantic relationship with their beloved. Mean duration of these relationships was 12.1 (S.D. $=9.4)$ months. The participants' score on the PLS was 7.8 (S.D. $=0.5$, range 7.0-8.5, Cronbach's alpha $=0.78$ ). The mean AIM score was 3.8 $($ S.D. $=0.5$, range 2.9-4.5, Cronbach's alpha $=0.88)$ and this score was not correlated with the PLS score, $r=0.13, p=0.61$. This suggests that the PLS scores were not confounded by a general tendency to experience emotions intensely.

Participants rated their romantic love (on a 9-point scale) to their beloved as 8.4 (S.D. =0.6), to their friend as 1.7 (S.D. =1.2), and to the unknown person 1.1 (S.D. $=0.3$ ). These ratings were significantly different, $F(2,34)=583.16$, $p<0.001$. Post-hoc comparisons showed that the participants experienced more romantic love for their beloved than for their friend, $p<0.001$, and the unknown person, $p<0.001$. And although the absolute difference in romantic love for the friend and the unknown person was small (0.6 on a 9-points scale), it was statistically reliable, $p=0.037$. The participants rated the beauty of their beloved as $8.2($ S.D. $=0.7)$, of their friend as 5.1 (S.D. $=1.3)$, and of the unknown person as $4.8($ S.D. $=2.0)$. These ratings were significantly different, $F(2,34)=33.50$, $p<0.001$. Post-hoc comparisons revealed that participants perceived their beloved as more beautiful than their friend, $p<0.001$, and the unknown person, $p<0.001$. The perceived beauty of the friend and unknown person did not differ, $p=0.45$.

Furthermore, the separate sample of participants who were unaware of the purpose of the study and unfamiliar with the people on the photographs, rated the beauty of the faces of the beloved condition as $4.4($ S.D. $=1.1)$, of the friend condition as 4.4 (S.D. $=1.0$ ), and of the unknown person condition as 6.3 (S.D. $=1.1)$. These ratings were significantly different, $F(2$, $38)=64.24, p<0.001$. Post-hoc comparisons showed that the faces in the unknown person condition were perceived as more beautiful than the faces in the beloved condition, $p<0.001$, and the friend condition, $p<0.001$. In contrast, the faces in the beloved and friend conditions did not differ in beauty, $p=0.77$.

Finally, the mean number of correctly answered questions concerning the identity of the faces was 11.5 out of 12 , indicating that the participants were alert during data acquisition.

\subsection{Event-related potentials}

The grand average ERPs for the faces of the beloved, friend, and unknown person are shown in Fig. 1. Visual inspection of the ERPs reveals that the faces in general elicited the usual N1, $\mathrm{P} 2$, fronto-central N2 components, and the expected late positivity with a parietal maximum.

For the mean activity in the 140-200 ms time window, none of the effects were significant, all $F \mathrm{~s}<1.72$, all $p \mathrm{~s}>0.18$.

Fig. 2 displays the scalp topography of the electrophysiological responses to the three faces in the $200-400 \mathrm{~ms}$ time window. Note that the anterior activity is negative, whereas the posterior activity is positive. In this time window, the main effect of condition was significant, $F(2,34)=4.37, \varepsilon=0.79$, $p=0.030$. Post-hoc comparisons revealed a nearly significant difference between the beloved and unknown person only, 


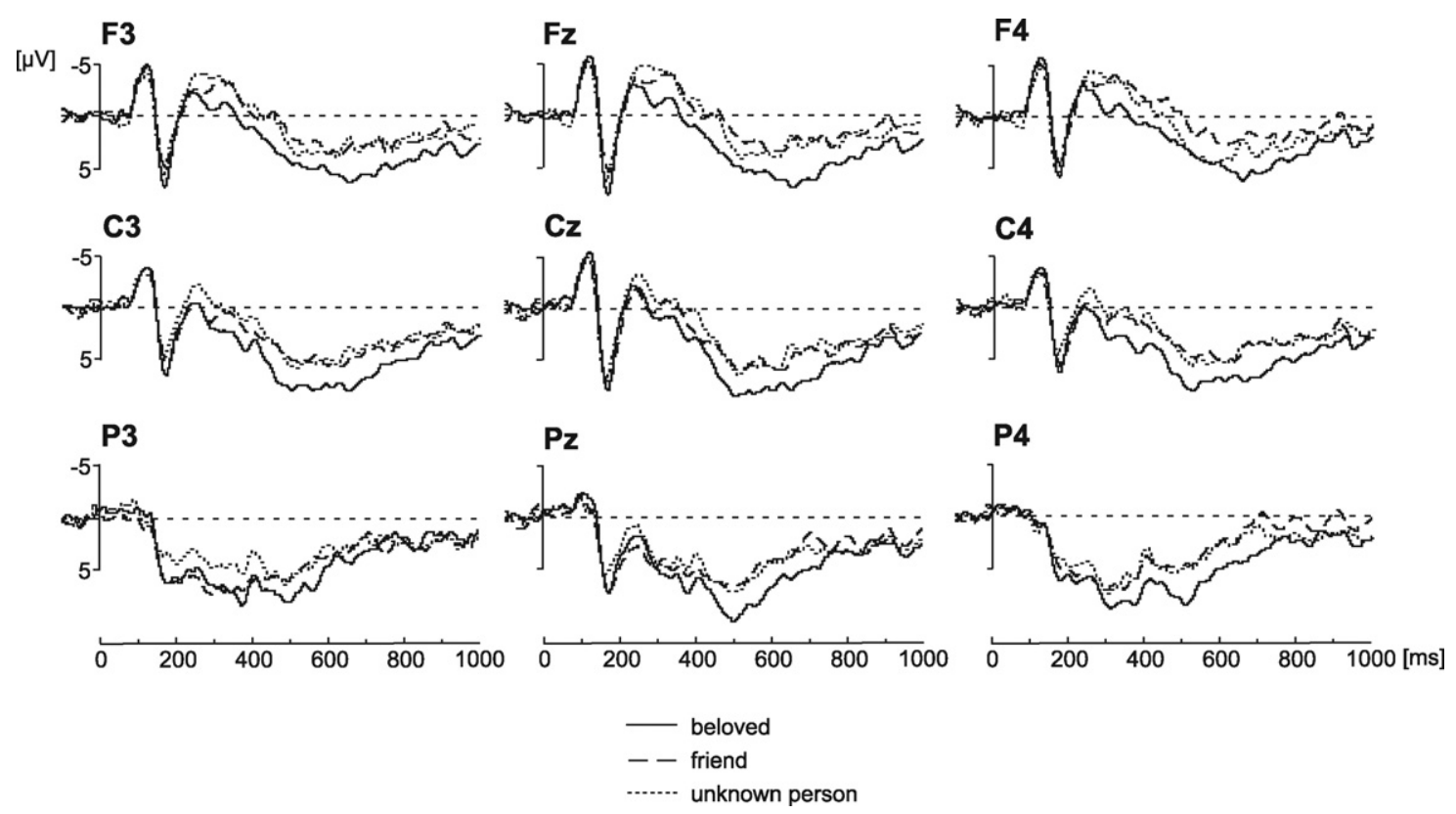

Fig. 1. Grand-average ERPs of the beloved (solid line), friend (dashed line), and unknown person (dotted line), positive down.

$p=0.058$, other $p \mathrm{~s}>0.14$, indicating that the waveform for the beloved was less negative than the waveform for the unknown person. Moreover, there was a trend towards an interaction of laterality and condition, $F(4,68)=2.59, \varepsilon=0.70, p=0.067$. Post-hoc comparisons showed that the condition effects were present mainly at lateral electrodes. Over the left hemisphere, the beloved elicited less negativity than the unknown person did, $p=0.008$. Over the right hemisphere, the waveform for the beloved was less negative than both the friend, $p=0.018$, and the unknown person, $p=0.017$, all other $p \mathrm{~s} \geq 0.058$.

Fig. 3 depicts the scalp topography of electrophysiological responses to the three faces in the $400-700 \mathrm{~ms}$ time window. It can be seen that the positivity elicited by the faces is widely distributed across the scalp and has a centro-parietal maximum, confirming the notion that it concerns the LPP. Further, this LPP appears to be most pronounced in response to the face of the beloved. Indeed, the main effect of condition was significant, $F(2$, $34)=4.63, \varepsilon=0.95, p=0.023$. Post-hoc comparisons demonstrated that the LPP for the beloved was larger than the LPP for both the friend, $p=0.007$, and the unknown person, $p=0.042$. The LPP for the friend and unknown person did not significantly differ from each other, $p=0.77$. None of the interactions involving condition were statistically reliable, all $F \mathrm{~s}<1.51$, all $p s>0.22$, implying that the condition effect was equivalent across the different electrodes. In order to address the influence of the perceived beauty of the faces on LPP amplitude at electrode $\mathrm{Pz}$, correlations between these measures were calculated. Such a correlation was observed neither for the stimulus set as a whole, $r=0.15, p=0.27$, nor for the stimuli of the three conditions separately, $-0.13 \leq$ all $r \mathrm{~s} \leq 0.10$, all $p \mathrm{~s} \geq 0.61$.

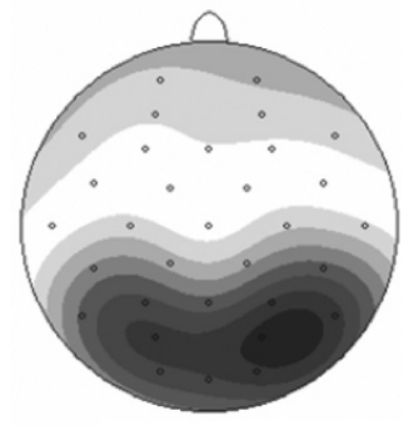

beloved

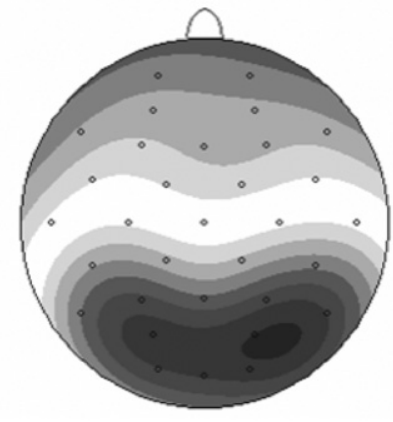

friend

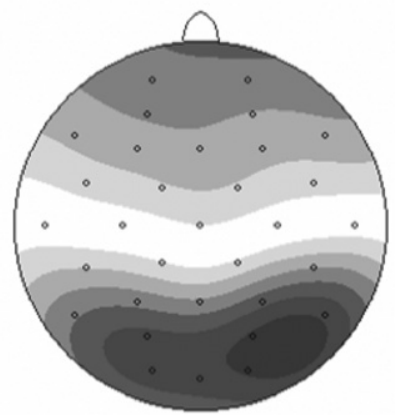

unknown person

$200-400 \mathrm{~ms}$

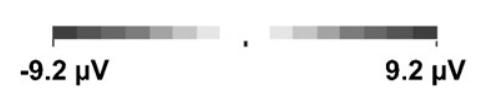

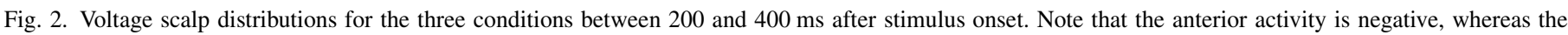
posterior activity is positive. 


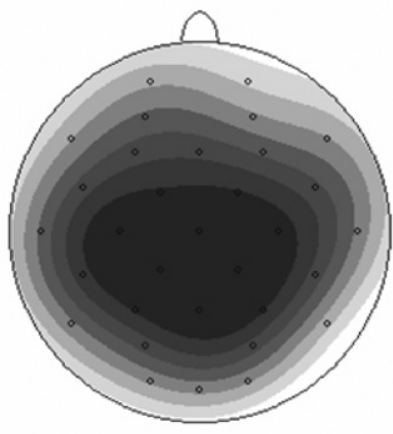

beloved

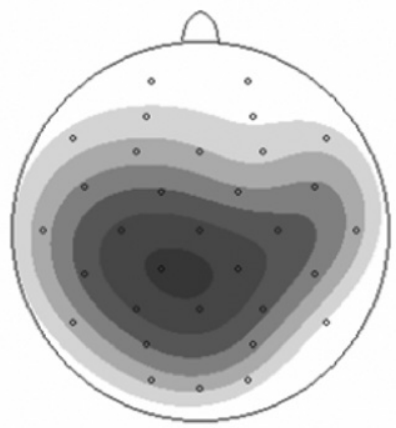

friend

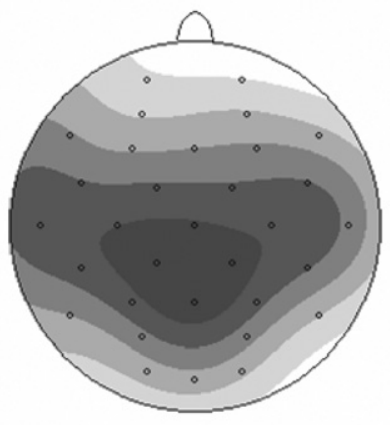

unknown person

400-700 ms

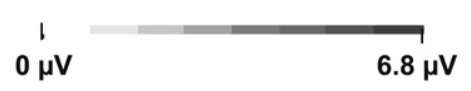

Fig. 3. Voltage scalp distributions for the three conditions between 400 and $700 \mathrm{~ms}$ after stimulus onset.

\section{Discussion}

The goal of this study was to examine the effect of loverelated facial stimuli on event-related potentials. The LPP was of greatest interest, since this potential has previously been found to be amplified for emotional stimuli and is thought to index motivated attention (e.g. Cuthbert et al., 2000; Polich, 2003; Schupp et al., 2004a; Stormark et al., 1995). As discussed in the introduction, the term motivated attention reflects the finding that more attention is allocated to emotional than to comparable neutral stimuli. Because the photograph of a certain face has a very special meaning to the individual that is in love with the depicted person, it was hypothesized that the LPP would be enhanced for the face of a beloved, even when compared to two other emotional stimuli, namely the face of a friend and of an unknown, beautiful person.

As expected, we found that the LPP (from $400 \mathrm{~ms}$ after stimulus onset) was most pronounced for the face of the beloved at frontal, central, and parietal sites. This suggests that the cortical neural response was more activated by faces associated with romantic love than by faces associated with familiarity or beauty only. Furthermore, it implies that more attention was allocated to the beloved than to the friend and the unknown person.

It is interesting that differences in motivated attention are found between the beloved and the two other categories although all three categories are emotionally significant. Previous research by Schupp et al. (2004a) has shown something similar. Using pleasant, unpleasant, and neutral (IAPS) pictures, they showed that both picture valence and the specific picture content influenced the LPP. Within the pleasant pictures, sexually explicit pictures and pictures of romantic scenes elicited larger LPPs than sports pictures did. The researchers explain these findings by assuming that sports pictures have a smaller effect on the motivational systems in the brain. The same line of reasoning could be applied to the present findings. It is plausible that motivational systems are more activated by the face of a beloved, than by the face of a friend or unknown, beautiful person. That is, the tendency to approach a beloved is presumably larger than the tendency to approach a friend or an unknown, beautiful person.

Some previous studies have demonstrated that the LPP is enhanced by facial familiarity. Eimer (2000), for example, observed greater LPPs for famous faces compared to unfamiliar faces. Similarly, in a study by Herzmann et al. (2004) the LPP seemed enhanced for both personally familiar and famous faces, compared to unfamiliar faces, but unfortunately Herzman and colleagues did not statistically test this. In the present study, the friend condition was included to control for familiarity. Still, it is possible that the participants felt more familiar with their beloved than with their friend, which might be the reason that the LPP was enhanced in response to the beloved. However, the absence of a difference between the LPPs for the friends and the unknown persons, speaks against modulation of the LPP by familiarity in the current study.

We attempted to control for beauty of the faces by including a beautiful face that was unknown to the participants. Objectively, this face was indeed more beautiful than the faces of the beloved and friends, as indicated by the ratings of the separate sample of men and women. The infatuated participants, however, perceived their beloved as most beautiful. This implies that the face of the beloved did not exhibit certain characteristics that are generally considered to be beautiful, whereas the beautiful unknown persons did. In other words, finding one's beloved beautiful, and other beautiful people not, appears to be a result of the state the observer. Even so, the perceived beauty of the beloved could have caused the amplification of the LPP, given that previous studies have shown that the LPP amplitude was larger for attractive compared to unattractive faces (Johnston and Oliver-Rodríguez, 1997; Oliver-Rodríguez et al., 1999). Yet, we did not observe a correlation between the perceived beauty and the accompanying LPP amplitudes. Thus it can be concluded that, while perceiving a beloved as beautiful appears to be a property of romantic love, it was presumably not responsible for the increased LPP amplitude in response to the beloved in the current study. 
Previous studies have shown that the LPP amplitude diminished across stimulus repetitions (Biondi et al., 2005; Codispoti et al., 2006a; see also Codispoti et al., 2006b). Because each of the faces was presented 30 times, the increased LPP amplitude in response to the beloved could have been caused by delayed or decreased habituation across repetitions to the face of the beloved than to the faces of the friend and unknown person. However, the above mentioned studies have also shown that the emotional modulation of the LPP was unaffected by stimulus repetitions. Even after as many as 60 stimulus presentations, unpleasant and pleasant pictures elicited a similar enhancement of the LPP amplitude as at the first presentations (Biondi et al., 2005; Codispoti et al., 2006a; see also Codispoti et al., 2006b).

As mentioned in the introduction, the LPP is influenced by task relevance and stimulus probability (Picton, 1992). In this study, each of the three faces appeared with the same probability and were equally relevant for the participants' task, since the three questions about the identity of the faces occurred with similar probability. However, the participants were aware that the study concerned romantic love and may thus have experienced the photograph of the beloved as a target stimulus. Moreover, the real-life probability of the faces may not be equal. That is, participants had never encountered the unknown person, and might see their beloved more often than their friend. On the other hand, the beloved is a unique person, whereas the friend and unknown person are part of a small and large group, respectively, thus the photographs represent object categories of different sizes. Therefore, the factors task relevance and stimulus probability may have confounded the present results. And although the present results are in line with previous research regarding emotions and motivations, more research is needed to more clearly dissociate the influence of task-related from love-related factors, insofar as possible.

Between 200 and $400 \mathrm{~ms}$ after stimulus onset, the $\mathrm{N} 2$ was less pronounced for the face of the beloved than for the unknown person. Similarly, Nessler et al. (2005) have observed a decreased N2 between 200 and $450 \mathrm{~ms}$ post-stimulus onset for famous compared to non-famous faces and interpreted this as semantic familiarity reflecting the retrieval of face identity information from semantic memory. Thus, the current finding of a decreased $\mathrm{N} 2$ for the face of the beloved may be due to increased familiarity with the beloved, although no differences between the friend and the unknown person were observed. Schweinberger and Burton (2003) have suggested that the frontal modulations by familiarity observed in studies employing a linked mastoids reference, like the present study and the study by Nessler et al., is actually a reflection of the modulation of the N250r (or early repetition effect-ERE), which can be obtained when employing an average reference. The N250r occurs between 200 and $350 \mathrm{~ms}$, is augmented for personally familiar and famous as compared to unfamiliar faces, and is maximal near the mastoids (which is the reason that it can not be obtained with a linked mastoids reference) (e.g. Herzmann et al., 2004). In addition, in previous studies regarding facial expressions, the $\mathrm{N} 2$ has been found to be smaller for faces with emotional expressions compared to neutral faces, although these differences were present mainly at fronto-central electrodes (Eimer and Holmes, 2002, 2007). This implies that, apart from familiarity, the emotional nature of faces may have influenced this early component as well.

A few of our participants appeared to have been in love for quite a long time. Some researchers have, however, assumed that romantic love usually lasts no more than 18 months (Fisher et al., 2002; Marazziti et al., 1999), where after it may convert into a much calmer state, namely attachment. Attachment comprises the maintenance of close contact to the loved person combined with feelings of calmness, comfort, and emotional union, without the abundant and overwhelming feelings and responses of romantic love (Fisher et al., 2002). Four of the participants in the present study had been in love for more than 18 months, but they nevertheless appeared to experience romantic love as reflected by their PLS scores (range 7.7-8.5). Assuming that responses to stimuli related to a beloved decrease with time in love, the inclusion of these participants probably diminished the power to find any differences between the beloved and the friend. Nevertheless, differences did occur.

In conclusion, we report here the first ERP data showing that faces of beloved ones elicit an enhanced LPP, compared to faces of friends or faces of unknown, beautiful people. Further, interpreting this LPP as motivated attention, romantic love seems to be accompanied by enhanced attention, as suggested by Fisher et al. (2002). In the light of the evolution theory, this increased attention during romantic love may promote the proliferation of ones genes, by supporting successful reproduction. From a behavioral perspective, it may explain some of the behavior of infatuated people, such as the tendency to stare and the fact that infatuated people tend to think about their beloved almost the entire day (Fisher et al., 2002).

\section{References}

Amrhein, C., Mühlberger, A., Pauli, P., Wiedemann, G., 2004. Modulation of event-related brain potentials during affective picture processing: a complement to startle reflex and skin conductance response? International Journal of Psychophysiology 54, 231-240.

Aron, A., Fisher, H., Mashek, D., Strong, G., Li, H., Brown, L.L., 2005. Reward, motivation, and emotion systems associated with early-stage intense romantic love. Journal of Neurophysiology 94, 327-337.

Aron, A., Fisher, H.E., Strong, G., 2006. Romantic love. In: Vangelisti, A.L., Perlman, D. (Eds.), Cambridge Handbook of Personal Relationships. Cambridge University Press, Cambridge, pp. 595-614.

Ashley, V., Vuilleumier, P., Swick, D., 2004. Time course and specificity of event-related potentials to emotional expressions. Neuroreport 15, 211-216.

Bartels, A., Zeki, S., 2000. The neural basis of romantic love. Neuroreport 11, 3829-3834.

Biondi, S., De Cesarei, A., Cardinale, R., Codispoti, M., 2005. What is the fate of unattended emotional stimuli? Cortical and behavioural correlates of affective habituation. Psychophysiology 42, S36.

Codispoti, M., Ferrari, V., Bradley, M.M., 2006a. Repetitive picture processing: autonomic and cortical correlates. Brain Research 1068, 213-220.

Codispoti, M., Ferrari, V., De Cesarei, A., Cardinale, R., 2006b. Implicit and explicit categorization of natural scenes. In: Anders, S., Ende, G., Junghöfer, M., Kissler, J., Wildgruber, D. (Eds.), Progress in Brain Research: Understanding Emotions, vol. 156. Elsevier Science, Boston, pp. 53-65. 
Compton, R.J., 2003. The interface between emotion and attention: a review of evidence from psychology and neuroscience. Behavioral and Cognitive Neuroscience Reviews 2, 115-129.

Cuthbert, B.N., Schupp, H.T., Bradley, M.M., Birbaumer, N., Lang, P.J., 2000. Brain potentials in affective picture processing: covariation with autonomic arousal and affective report. Biological Psychology 52, 95-111.

Dietrich, D.E., Emrich, H.M., Waller, C., Wieringa, B.M., Johannes, S., Münte, T.F., 2000. Emotion/cognition-coupling in word recognition memory of depressive patients: an event-related potential study. Psychiatric Research 96, 15-29.

Dolcos, F., Cabeza, R., 2002. Event-related potentials of emotional memory: encoding pleasant, unpleasant, and neutral pictures. Cognitive, Affective, and Behavioral Neuroscience 2, 252-263.

Eimer, M., 2000. Event-related potentials distinguish processing stages involved in face perception and recognition. Clinical Neurophysiology 111, 694-705.

Eimer, M., Holmes, A., 2002. An ERP study on the time course of emotional face processing. Neuroreport 13, 427-431.

Eimer, M., Holmes, A., 2007. Event-related brain potential correlates of emotional face processing. Neuropsychologia 45, 15-31.

Fisher, H.E., 1998. Lust, attraction, and attachment in mammalian reproduction. Human Nature 9, 23-52.

Fisher, H.E., 2000. Lust, attraction, attachment: biology and evolution of the three primary emotion systems for mating, reproduction, and parenting. Journal of Sex Education and Therapy 25, 96-104.

Fisher, H.E., Aron, A., Mashek, D., Li, H., Brown, L.L., 2002. Defining the brain systems of lust, romantic attraction, and attachment. Archives of Sexual Behavior 31, 413-419.

Fisher, H., 2004. Why We Love. Henry Holt and Company, New York.

Fisher, H., Aron, A., Brown, L.L., 2005. Romantic love: an fMRI study of a neural mechanism for mate choice. The Journal of Comparative Neurology 493, 58-62.

Franken, I.H.A., Stam, C.J., Hendriks, V.M., Van den Brink, W., 2003. Neurophysiological evidence for abnormal cognitive processing of drug cues in heroin dependence. Psychopharmacology 170, 205-212.

Franken, I.H.A., Booij, J., Van den Brink, W., 2005. The role of dopamine in human addiction: from reward to motivated attention. European Journal of Pharmacology 526, 199-206.

Gratton, G., Coles, M.G., Donchin, E., 1983. A new method for off-line removal of ocular artifact. Electroencephalography and Clinical Neurophysiology $55,468-484$.

Hatfield, E., 1998. The passionate love scale. In: Davis, C.M., Yarber, W.L., Bauserman, R., Schreer, G., Davis, S.L. (Eds.), Handbook of SexualityRelated Measures. Sage Publications, Thousand Oaks, pp. 449-451.

Herzmann, G., Schweinberger, S.R., Sommer, W., Jentzsch, I., 2004. What's special about personally familiar faces? A multimodal approach. Psychophysiology 41, 688-701.

Johansson, M., Mecklinger, A., Treese, A., 2004. Recognition memory for emotional and neutral faces: an event-related potential study. Journal of Cognitive Neuroscience 16, 1840-1853.

Johnston, V.S., Oliver-Rodríguez, J.C., 1997. Facial beauty and the late positive component of event-related potentials. The Journal of Sex Research 34, $188-198$.
Langeslag, S.J.E., 2006. Liefde is een motivatie, niet een emotie: een neurobiologische benadering [Love is a motivational state, not an emotion: a neurobiological approach]. De Psycholoog 41, 260-265.

Larsen, R.J., Diener, E., 1987. Affect intensity as an individual difference characteristic: a review. Journal of Research in Personality 21, 1-39.

LeDoux, J.E., 1996. The Emotional Brain: The Mysterious Underpinnings of Emotional Life. Simon \& Schuster, New York.

Lipp, O.V., Waters, A.M., 2007. When danger lurks in the background: attentional capture by animal fear-relevant distractors is specific and selectively enhanced by animal fear. Emotion 7, 192-200.

Marazziti, D., Akiskal, H.S., Rossi, A., Cassano, G.B., 1999. Alteration of the platelet serotonin transporter in romantic love. Psychological Medicine 29, 741-745.

Namkoong, K., Lee, E., Lee, C.H., Lee, B.O., An, S.K., 2004. Increased P3 amplitudes induced by alcohol-related pictures in patients with alcohol dependence. Alcoholism: Clinical and Experimental Research 28, 1317 1323.

Nessler, D., Mecklinger, A., Penney, T.B., 2005. Perceptual fluency, semantic familiarity and recognition-related familiarity: an electrophysiological exploration. Cognitive Brain Research 22, 265-288.

Oliver-Rodríguez, J.C., Guan, Z., Johnston, V.S., 1999. Gender differences in late positive components evoked by human faces. Psychophysiology 36, 176-185.

Picton, T.W., 1992. The P300 wave of the human event-related potential. Journal of Clinical Neurophysiology 9, 456-479.

Polich, J., 2003. Theoretical overview of P3a and P3b. In: Polich, J. (Ed.), Detection of Change: Event-Related Potential and fMRI findings. Kluwer Academic Publishers, Boston, pp. 83-98.

Pollatos, O., Kirsch, W., Schandry, R., 2005. On the relationship between interoceptive awareness, emotional experience, and brain processes. Cognitive Brain Research 25, 948-962.

Schupp, H.T., Cuthbert, B.N., Bradley, M.M., Hillman, C.H., Hamm, A.O., Lang, P.J., 2004a. Brain processes in emotional perception: motivated attention. Cognition and Emotion 18, 593-611.

Schupp, H.T., Öhman, A., Junghöfer, M., Weike, A.I., Stockburger, J., Hamm, A.O., 2004b. The facilitated processing of threatening faces: an ERP analysis. Emotion 4, 189-200.

Schupp, H.T., Flaish, T., Stockburger, J., Junghöfer, M., 2006. Emotion and attention: event-related brain potential studies. In: Anders, S., Ende, G., Junghöfer, M., Kissler, J., Wildgruber, D. (Eds.), Progress in brain research: Understanding emotions, vol. 156. Elsevier Science, Boston, pp. 31-51.

Schupp, H.T., Stockburger, J., Codispoti, M., Junghöfer, M., Weike, A.I., Hamm, A.O., 2007. Selective visual attention to emotion. The Journal of Neuroscience 27, 1082-1089.

Senior, C., 2003. Beauty in the brain of the beholder. Neuron 38, 525-528.

Stormark, K.M., Nordby, H., Hugdahl, K., 1995. Attentional shifts to emotionally charged cues: behavioural and ERP data. Cognition and Emotion 9, 507-523.

Schweinberger, S.R., Burton, A.M., 2003. Covert recognition and the neural system for face processing. Cortex 39, 9-30.

Van Strien, J.W., 1992. Classificatie van links- en rechtshandige proefpersonen [Classification of left-handed and right-handed test subjects]. Nederlands Tijdschrift voor de Psychologie 47, 88-92. 